\title{
Writing a copyright policy for the campus
}

\author{
By Tjalda Nauta Belastock
}

\section{How to bring the Copyright Act into focus for faculty and staff}

opyright. The word is on all our lips, in all our minds, and we feel faint tremors of fear thinking about the various ways in which we personally and collectively might be violating the Copyright Act of 1976. We hear about "the Kinko case" and "the Texaco case" and wonder how we would feel if it was our institution being hauled into court because of copyright infringement. Hundreds of articles have been written about copyright issues from the point of view of publishers, authors, lawyers, and librarians. There is even a listserv devoted exclusively to discussions of copyright issues (cnicopyright@cni.org). Certainly there must be enough information in both print and electronic formats available to get a fairly good idea of what the law is and how it can and should be followed in our libraries.

\section{Involving the campus community}

That is what we thought too when we took on the daunting task of putting together a copyright policy for our library's Reserve Book Room and, in fact, we were quite overwhelmed by the amount of material we would have to gather and read. We soon agreed that to go through all this work and effort to put together a policy for the Reserve Book Room would have more effect if we included the entire campus in its scope. We witnessed while working in the Reserve Book Room daily examples of flagrant violations of copyright law perpetrated by faculty and staff. If these violations were allowed on the rest of the campus, why should only the library make attempts to comply with the law? We started thinking about who else on campus might be running risks of copyright violations: the copy center, the campus book store, the campus print shop, and all the departmental and administrative secretaries in the course of following instructions from their bosses. And how about the faculty themselves? Notoriously individualistic and with strong antipathies to being told how to do things, they would also have to be brought into compliance along with the rest of the campus.

After conversations with members of the various constituencies, we discovered that they too had been worrying for some time about how to come into comfortable, consistent compliance with the Copyright Act. It was therefore decided to form a committee to write a copyright policies booklet, with each of the interested groups represented by at least one member. The book store, the print shop, the copy center, media services, and computer services all agreed to send a representative to the first meeting. Next, to ensure faculty involvement in the project, we contacted the dean of the faculty. Upon hearing our concerns, the dean asked why we needed a new copyright policy when the Faculty Manual already stated that the Copyright Act of 1976 was to be followed by all faculty? We responded that admonitions to follow the act did not give the faculty any information about how to do that. He then gave his blessing to our committee, and agreed to support whatever procedures the committee decided upon. He designated the associate undergraduate dean as the faculty's official representative to the committee.

So one day the following people were all together in one room: the manager of the book

Tjalda Nauta Belastock is associate library director for information services at Bentley College; e-mail: thelastock@bentley.edu 
store, the manager of the print shop, the associate dean of the undergraduate college, the supervisor of the copy center, a representative from the computer center, and from the library, the circulation supervisor, the reserves coordinator, the interlibrary loan supervisor, the associate library director for media services, and the associate library director for information services.

\section{Proof or assumptions of compliance}

Our first step was to share with each other articles about copyright and examples of policies and guidelines that we had been able to gather from other academic institutions including Wellesley College and Boston University. In addition, we were each given the copyright booklet recently published jointly by the National Association of College Stores, the Association of American Publishers, and the Association of American Lniversity Presses. We also found ourselves regularly consulting Laura Gasaway and Sarah Wiant's Libraries and Copyright: A Guide to Copyright Law in the 1990's (Special Libraries Assoc., 1994). After a review of these various materials, we discovered that most photocopying and duplicating policies fell into one of two categories: "proof of compliance" and "assumption of compliance." For example, the Association of College Stores has a very strict "proof of compliance" policy, requiring in all cases that proof of permission obtained and of royalties paid must be presented before the materials can be reproduced. The Wellesley College policy, however, is more trusting, and allows copiers to declare verbally that the permissions have been obtained

In discussions with various faculty members about the copyright issues, we discovered that proof of compliance would not only not work, but would most likely discourage any efforts at copyright compliance. In our next meeting, therefore, we decided to use the "assumption of compliance" model, which requires copiers to state that they either have the appropriate permissions or that they are in the process of obtaining the permissions. We would have to trust that they would do their best to be in compliance with the act.

\section{Obtaining permissions}

Second, we discussed the various methods by which copiers might go about obtaining copyright permissions. Obtaining permissions can be a daunting and frustrating exercise, as any- one who has done it knows. First it must be determined who holds the copyright to the article, then the addresses must be found, then a letter must be written giving details of what title, article, situation, and time span the permission is being requested for. Then it can be weeks before a response is received, not always granting permission. It can be a very frustrating experience, and many copiers would rather not endure it. To make life, and copyright permissions, easier we decided to encourage faculty and staff to use the Copyright Clearance Center (CCC) in Danvers, Massachusetts, to obtain most of the permissions needed. The CCC will obtain copyright permissions from any of the copyright holders and publishers with whom they have agreements for a flat fee of $\$ 100$ per year and a small per-page service charge. However, although the list is long, not all publishers are included, requiring that copyright holders must, in many cases, still be written to directly for permission. In the policies booklet we therefore decided to include various form letters that could be photocopied, filled out, and sent off to publishers or media producers. We also decided to include copies of the CCC forms.

\section{Performances and computer issues}

In addition to the traditional library-related copyright issues, we also hammered out questions about off-air videotaping, public showings versus private showings of films and videos, and the problem of defining fair use in the context of nonprint media. We discovered that while the Copyright Act of 1976 covers many of the issues dealing with print materials, when it came to nonprint media we were quite without guidance. Moreover, where there was precedent, it was often of a very restrictive nature, not at all conducive to the educational setting. We finally decided to include commonly accepted practices in the area of nonprint media in academic settings insofar as we were able to determine them from informal discussions with other colleges and universities. We also decided it was more appropriate to write them into our Copyright Policies booklet in the form of Q\&A rather than as abstract policy.

The computer center component of the policies was easier to write since copyright issues in that area have for many years been defined by the software vendors, leaving very little room for discussion or interpretation by users. This was also written in a Q\&A format because we 
felt that it helped users to realize in what ways they could be violating copyright inadvertently. We also included in this section a discussion of the restrictions and limitations on our electronic services, such as Lexis/Nexis and Dow-Jones.

\section{Sharing the costs}

Once all the component parts of the policies were put together we decided we finally had to attack the problem of the copyright permissions procedures and costs. Full of optimism, we had given the CCC a trial run, using an account previously set up by the library, but quickly discovered that the administration of the copyright permission process for the entire campus would totally overwhelm the library reserves staff. Either additional staff would have to be hired, an unlikely scenario these days, or we would have to find some way for individual departments to administer the copyright process. This problem was not resolved until nearly the end of the policy preparation process. Seeing no other way, we again approached the dean of the faculty who, on hearing the extent of the problem and realizing that one solution would require creating a new position, decided to charge the various departments with the implementation of CCC procedures. Therefore, in a meeting of academic department chairs, he charged them with the task of setting up CCC accounts as needed. It was made clear to the chairs that copyright compliance would be expected from then on, and that the departments would be responsible for administering the copyright requests and fees for their department members. Surprisingly, there was almost no protest, although it was clear that the departments would have to shoulder the costs and burdens of administration themselves.

While the document was still on the lawyer's desk awaiting final approval, we realized that the printing and distribution of the policies would also be key to their implementation. This time we approached the vice-president for business and finance, who agreed to underwrite the production costs. We explained that what we had in mind was not merely a photocopied set of pages stapled together, but a really serious-looking booklet with a proper artistically designed cover to give the policies inside some psychological heft. We knew what we were planning would be fairly expensive, but the VP enthusiastically backed us in our plan. The graphics producer in our Media Services De- partment was charged with coming up with an interesting and attractive cover design. A few months later the campus print shop delivered 1,000 booklets to be distributed initially at the opening faculty meeting in September.

\section{Conclusions}

It should be noted that while the intention of the Copyright Policies booklet was to bring the entire campus into compliance, we feel we had much more success and visibility with the faculty than with the various administrative units on campus. Since publication of the policies, numerous telephone calls, e-mail messages and informal discussions have been received from the faculty by the committee members. We made a concerted effort to distribute through campus mail multiple copies of the booklet addressed to the secretaries of administrative units, asking them to distribute them among the various members of their departments. But while this has, we hope, "put the word out," we have no real evidence that the policies are being followed, or that any changes have $\mathrm{OC}^{-}$ curred in the photocopying habits of the various campus administrators. However, about one month after the initial distribution of our Copyright Policies for Bentley College, both the manager of the print shop and the manager of the copy shop expressed surprise at the fact that usage of their operations was significantly lower than in previous years, indicating, they felt, that at least some of the members of the college community were reining in the uncontrolled photocopying of previous years.

One rueful aside to our experience is that after the booklet was printed, we noticed that we had neglected to include the familiar copyright symbol and the name of the college to inclicate that it holds the copyright to the document! We were faintly consoled by the knowledge that according to the Copyright Act, copyright is implicitly held by the writer(s) of any document and does not have to be specifically registered or indicated.

The pressure building over time on the other various units to "do something about copyright" was what brought our committee together, and what finally got the administration to acknowledge the problem and to give us its support. It seems quite apparent to us that in most academic institutions, as at Bentley College, the library could quite naturally play the role of catalyst for such a project and can be a strong clriving force in its process and implementation. 


\section{Enhance Your Knowledge of Library Tools and Resources With These Insightful Publications From The Haworth Press, Inc.!}

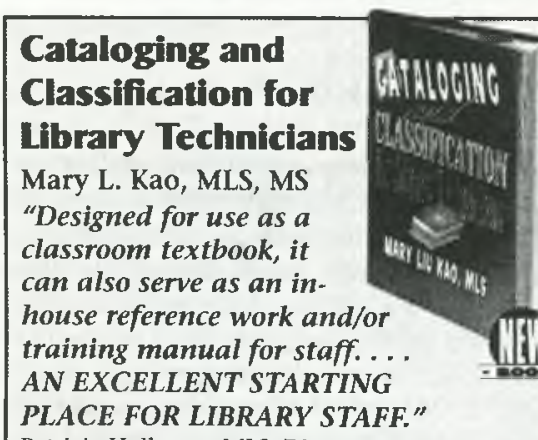

Patricia Holloway, MLS, Director,

Eastern Connecticut Libraries, Inc., (Library

Consortium), Norwich, Connecticut

Selected Contents: Library Catalogs • Tools Used for Cataloging - Descriptive Cataloging

- Subject Headings - Classification - The

Cataloging Department - More

\$24.95 hard. ISBN: 1-56024-344-9.

$\$ 14.95$ soft. ISBN: $1-56024-345-7$.

1995. $137 \mathrm{pp}$. with Index.

\section{Technical Services Management, 1965- 1990}

A Quarter Century of Change and a Look to the Future

Edited by

Linda C. Smith, $\mathrm{PhD}$, and Ruth C. Carter, PhD

Technical Services Management surveys and analyzes technical services in libraries from 1965 to 1990 , as well as identifying trends that continue to impact technical services operations in libraries today.

Selected Contents: Trends in Technical Services - A History of the Online Catalog in North America - Authority Control

- Descriptive Cataloging - More

\$49.95 hard. ISBN: 1-56024-960-9.

Text price ( $5+$ copies): $\$ 19.95$.

1995. 370 pp. with Index.

\section{Librarians on the Internet}

Impact on Reference Services Edited by Robin Kinder, MLS "Succeeds in demonstrating that the Internet is becoming increasingly a challenging but practical and

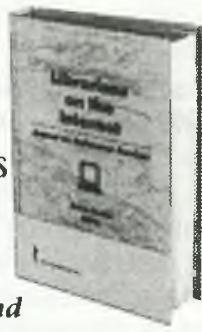
manageable tool in the reference librarian's ever-expanding armory." Reference Reviews

Here is one of the first books to focus on the Internet's impact on library services. The questions this book answers--and those it raises-inform and challenge librarians as they forge ahead into the future.

Selected Contents: Introducing Internet Services - Getting Started on the Net - Gopher Searching Using VERONICA • Science Resources on the Internet - Internet's Impact on Reference Services - The Internet and Reference Librarians - The Internet as a Reference and Research Tool - The Internet and OCLC • More (A monograph published simultaneously as The Reference Librarian, Nos. 41/41.) $\$ 69.95$ hard. ISBN: 1-56024-672-3. Text price $(5+$ copies $)$ : $\$ 24.95$. 1994. 410 pp. with Index.

\section{ALSO OF INTEREST . . .}

\section{- Career Planning and Job Searching} In the Infomation Age

(A monograph published simultaneously as

The Reference Librarian, No. 55.)

\$29.95 hard. ISBN: 1-56024-838-6.

Text price $(5+$ copies): $\$ 19.95$.

Available Summer 1996. Approx. 137 pp.

\section{- Managing Change in} Academic Ubraries

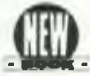

(A monograph published simultaneously as the Journal of Library Administration, Vol. 22, Nos. 2/3.) \$29.95 hard. ISBN: 1-56024-810-6.

Text price $(5+$ copies): $\$ 19.95$

Available Spring 1996. Approx. 172 pp. with Index.

The Haworth Press, Inc.

10 Alice Street, Binghamton, NY 13904-1580 USA Tel: 1-800-342-9678 / Fax: 1-800-895-0582 / E-mail: getinto@haworth.com

PAD96 